https://doi.org/10.24201/aap.2020.299

\title{
Presentación
}

\section{0, UN AÑO CRUCIAL PARA EL FORO ASIA-PACIFIC ECONOMIC COOPERATION (APEC) Y PARA LA REGIÓN DEL PACÍFICO}

JUAN JOSÉ RAMÍREZ BONILLA ORCID: https://orcid.org/0000-0001-6109-2269

El Colegio de México, A. C.

La declaración de la presidenta de la Cámara de Representantes del Congreso de los Estados Unidos, Nancy Pelosi, expresando su orgullo "con lo que se logró sobre el nuevo acuerdo comercial de Estados Unidos” (Pelosi, 2019), dice mucho acerca del futuro de la política económica internacional estadounidense: los resultados del proceso para el impeachment de Donald Trump y de la elección presidencial de 2020 serán irrelevantes; él o su sucesor, republicano o demócrata, seguirá construyendo el proyecto regional centrado sobre la economía estadounidense y cimentado con los acuerdos comerciales bilaterales negociados, hasta ahora, con Canadá, México, Corea y Japón.

El gobierno estadounidense está ahora lejos de la filosofía neoliberal del regionalismo abierto (de la liberalización comercial y financiera unilateral y voluntaria), impulsado, en 1993, por la primera administración Clinton en el foro Asia-Pacific Economic Cooperation (APEC). También ha tomado distancia del proteccionismo consensuado subyacente a los mal llamados “acuerdos de libre comercio", justificados mediante la fracción 5 del artículo XXIV del General Agreement on Tariffs and Trade (GATT). Ahora, con los acuerdos comerciales bilaterales arriba citados, la administración Trump pone en práctica un nuevo regionalismo, 
basado en la coerción derivada de las diferentes formas de dependencia estructural que mantienen las contrapartes con los Estados Unidos y utilizadas por dicha administración para imponer los intereses estadounidenses (Ramírez Bonilla, 2019).

El sistema económico global, en consecuencia, está en transición desde una fase marcada por el impulso estadounidense a los mecanismos multilaterales y los acuerdos comerciales basados en el proteccionismo consensuado hacia una nueva etapa determinada por el desentendimiento de la administración Trump de las instituciones multilaterales y también por el regionalismo estadounidense, acentuado por el proteccionismo coercitivo; se trata, en el fondo, de la imposición del derecho estadounidense como norma regulatoria de las relaciones internacionales de los Estados Unidos.

Aunque en términos generales APEC es un foro de diálogo y de concertación en temas de cooperación intergubernamental, la nueva política económica internacional de la administración Trump lo afecta directamente, tanto en su naturaleza multilateral como en dos de sus proyectos esenciales: las metas de Bogor y el Área de Libre Comercio de Asia-Pacífico (ALCAP). A este tema están dedicados los cinco capítulos de la sección temática de la edición 2020 del Anuario Asia Pacífico.

A la luz de la influencia regional de la disputa comercial sino-estadounidense, es posible demostrar que, en la tercera década del siglo, la región del Pacífico entra en una fase marcada por conflictos subregionales que alimentan y son alimentados por el conflicto sinoestadounidense. Los trabajos incluidos en el presente volumen ofrecen elementos abundantes y necesarios para sostener esta conclusión. En este marco y ante la insistencia de la administración Trump en desentenderse de las instituciones multilaterales, APEC gana importancia como mecanismo garante de la "contención, sin aislamiento", tanto de China como de los Estados Unidos.

\section{LA NATURALEZA DE APEC}

La naturaleza del foro como un mecanismo multilateral de diálogo y de consulta propio de la región del Pacífico fue puesta en duda por Donald Trump, en ocasión de su intervención en el APEC CEO Summit de 2017. En efecto, desde el preámbulo de su intervención el 
presidente de los Estados Unidos afirmó: "tengo el honor de compartir nuestra visión de un[a región] Indo-Pacífico libre y abiert[a]; un lugar donde las naciones soberanas e independientes, con diversas culturas y muchos sueños diferentes, puedan prosperar lado a lado, en libertad y en paz" (Trump, 2017).

La denominación “Asia-Pacífico" suele ser problemática, pues cada individuo o cada organización suele otorgarle el significado geográfico o político que desea; no menos complicado es el uso del término "Indo-Pacífico"; pero, a todas luces, la intención del señor Trump es más política que geográfica, pues tiene dos finalidades muy precisas: justificar los mecanismos puestos en práctica para proteger la economía estadounidense de la competencia china y la introducción de India como un contrapeso a la creciente influencia china en el foro APEC.

\section{China y la justificación moral del proteccionismo estadounidense}

La primera finalidad es poner en jaque a un gobierno chino que ha sabido utilizar el statu quo internacional para llevar a cabo las reformas económicas domésticas y para consolidar su posición económica tanto en la región del Pacífico como en el sistema global. En ese sentido, el discurso del ocupante de la Casa Blanca fue directo, aunque contradictorio:

Recientemente hice un excelente viaje a China, donde hablé abierta y directamente con el presidente Xi [Jiping], sobre las prácticas comerciales injustas de China y los enormes déficits comerciales que han producido con los Estados Unidos. Expresé nuestro fuerte deseo de trabajar con China para lograr una relación comercial que se lleve a cabo de manera justa e igualitaria.

El desequilibrio comercial actual no es aceptable. No culpo a China, ni a ningún otro país, de los cuales hay muchos, por aprovecharse comercialmente de Estados Unidos. Si sus representantes pueden salirse con la suya, es simplemente porque hacen su trabajo. Desearía que las administraciones anteriores de mi país hubieran visto lo que sucedía e hicieran algo al respecto. No lo hicieron, pero yo lo haré.

A partir de este día, competiremos de manera justa y equitativa. No vamos a permitir que se aprovechen más de los Estados Unidos (Trump, 2017). 
La contradicción en el discurso es flagrante: Trump desliza sus juicios de la racionalidad de los mecanismos económicos (la competencia comercial entre agentes económicos, con perdedores y ganadores) a la moral (prácticas comerciales injustas, una relación comercial justa e igualitaria, competencia justa y equitativa, juzgadas por los actores políticos). La consecuencia práctica necesaria está contenida en la frase final: en la competencia desigual entre actores económicos, éstos son sustituidos por los actores políticos para equilibrar las relaciones comerciales desiguales. Consciente de que la relación del gobierno estadounidense con cualquier otro gobierno del mundo es asimétrica y favorable para los Estados Unidos, Trump pone de realce el mecanismo privilegiado para imponer sus intereses a cada contraparte:

Haré acuerdos comerciales con cualquier nación de [la región] Indo-Pacífico que quiera ser nuestro socio y que cumpla con los principios del comercio justo y recíproco. Lo que ya no haremos es celebrar grandes acuerdos que nos atan las manos, que nos hacen renunciar a nuestra soberanía y que tornan prácticamente imposible su aplicación profunda (Trump, 2017).

La competencia entre actores económicos deja de ser determinada por sus ventajas o desventajas competitivas, para ser regulada por los entes políticos; así, el comercio es considerado justo, siempre y cuando se apegue a las reglas del derecho estadounidense (en detrimento del internacional) y satisfaga los intereses del ente político predominante en la relación bilateral asimétrica.

\section{India como contrapeso político en la región del Pacífico}

La segunda finalidad política del uso de la denominación "Indo-Pacífico" ha sido abrir una brecha en la política de membresías del foro, para introducir la necesidad de reconocer al gobierno de la India como un actor regional relevante:

En una región más amplia, los países fuera de APEC también están dando grandes pasos en este nuevo capítulo de [la región] Indo-Pacífico.

India celebra el 70 aniversario de su independencia. Es una democracia soberana, y, piensen en esto, de más de mil millones de personas. Es la democracia más grande del mundo. 
Desde que India abrió su economía, ha logrado un crecimiento asombroso y un mundo de oportunidades para su clase media en expansión. Y el primer ministro Modi ha venido trabajando para unir ese vasto país y toda su gente como uno solo... (Trump, 2017).

El lector advertido interpretará las loas a la democracia india como un juicio reprobatorio del carácter antidemocrático del régimen chino. Ahora bien, el señor Trump pasa por alto el hecho de que el sistema político indio está basado en un sistema de castas; en éste, la pertenencia religiosa se convierte en una línea divisoria social y política tanto entre los hinduistas como entre éstos y los otros grupos religiosos. Por eso, no es sorprendente que el Parlamento indio haya votado una ley para apresurar el otorgamiento de la ciudadanía a los migrantes provenientes de Afganistán, Bangladesh y Pakistán que profesen el hinduismo, el sijismo, el budismo, el jainismo, el zoroastrismo y el cristianismo; pero los musulmanes han sido excluidos de la iniciativa (Expansión, 2019). El animal político estadounidense no paró mientes en esos aspectos de la calidad de la democracia india, pues su interés principal era introducir al gobierno de la India en el juego de fuerzas político de APEC, como un contrapeso a la influencia de China.

En la órbita de APEC, los analistas se han apresurado en adoptar la noción "IndoPacífico" introducida por Donald Trump, dando por hecho la inclusión de la India en los procesos en curso en la región Asia-Pacífico; sin embargo, el recuento de los vínculos productivos, financieros y comerciales de la India con el resto del mundo muestra poca afinidad con los países participantes en APEC y, en contraste, una integración creciente con sus vecinos inmediatos. Por si eso no bastara, a principios de noviembre de 2019, el gobierno de la India rehusó firmar el Regional Comprehensive Economic Partnership (RCEP), que lo vincularía formalmente a la región asiática del Pacífico. Los medios señalaron que:

Una de las razones de la decisión de la India de no unirse al bloque comercial fue la creciente agitación contra el pacto, no sólo de la industria india, sino también de los grupos de agricultores. Representantes de una gran cantidad de sectores industriales, desde acero y productos de ingeniería hasta textiles y plásticos, pidieron al ministro de comercio e industria, Piyush Goyal, que los proteja contra las importaciones exentas de aranceles, provenientes de China (Sen, 2019). 
El gobierno indio ha privilegiado la estabilidad política interna y la preservación de su área de influencia regional sobre los riesgos que representa la vinculación comercial con una China mucho más competitiva que la India. Con ello, el señor Trump se ha visto privado de un peón importante sobre el tablero de la confrontación con China.

Para la administración Trump, este fracaso político ha sido parcial: si bien el gobierno indio ha decidido postergar su inclusión en el sistema Indo-Pacífico, privando al gobierno estadounidense de un aliado contra China, también ha creado un vacío en el proyecto RCEP promovido por las autoridades chinas para enfrentar la iniciativa estadounidense del Trans Pacific Partnership Agreement (TPP), primero, y, luego, la japonesa del Comprehensive and Progressive Agreement for Trans-Pacific Partnership (СРTPP).

En resumen, ante la formalización del CPTPP y del RCEP, el proyecto transregional de la administración Trump, basado en los acuerdos bilaterales con Canadá, México, Corea, Japón y, probablemente, la Unión Europea y el Reino Unido, aparece como el medio necesario para competir en mejores condiciones con una China que ha rebasado a los Estados Unidos en múltiples campos económicos, pero la cristalización de los tres macroproyectos de integración regional ha tenido como efecto colateral la puesta en entredicho de las dos iniciativas emblemáticas de APEC: las Metas de Bogor y el Área de Libre Comercio de AsiaPacífico (ALCAP).

\section{LOS INTRÍNGULIS DE LIBERALIZACIÓN} COMERCIAL Y FINANCIERA

Durante los preparativos de la primera reunión de jefes de Estado y de gobierno de APEC (denominada eufemísticamente Reunión de Líderes Económicos de APEC), el Eminent Persons Group (EPG) del foro difundió sus recomendaciones para construir una "comunidad económica de Asia Pacífico”. Ésta debía tener como vocación el libre comercio, practicado de manera unilateral y voluntaria por los miembros del foro, en beneficio propio y de todas las economías del mundo; esta concepción del libre comercio fue bautizada como "regionalismo abierto" (APEC, 1993) y se adoptó como objetivo primordial del foro durante la primera reunión de los líderes de APEC, organizada por el gobierno estadounidense en 1993. 
En 1994, la presidencia del foro correspondió al gobierno de Indonesia y durante la reunión de líderes en Bogor fueron adoptadas los Bogor Goals (traducidos en español indistintamente como las Metas de Bogor o los Objetivos de Bogor): en 2010, las economías desarrolladas de APEC suprimirían, unilateral y voluntariamente, todas las barreras opuestas a los flujos comerciales y financieros. En 2020, tocaría el turno a las economías en desarrollo de poner en práctica unilateral y voluntariamente la liberalización comercial y financiera. A partir de entonces, los representantes políticos introdujeron, en sus declaraciones, la referencia ritual al compromiso con las Metas de Bogor y comenzaron a proponer y adoptar mecanismos para alcanzarlas progresivamente. En su trabajo, incluido en el presente volumen, Eugenio Anguiano destaca el contexto económico global prevaleciente: la economía estadounidense entraba en la fase de expansión más larga de la posguerra y las economías asiáticas, especializadas en la producción y exportación de manufacturas, experimentaban sendos éxitos económicos gracias a la apertura económica progresiva.

Sin embargo, en 1997 el éxito asiático mostró sus límites ante el estallido de la primera gran crisis regional de la era de la globalización. Entre la crisis asiática de 1997 y la recesión estadounidense de 2001, la economía global entró en una fase de crecimiento cada vez más lento, interrumpido por la crisis del subprime market en 2007 y por la crisis financiera global durante 2008, 2009 y 2010. En el ámbito político, el texto de Juan José Ramírez Bonilla, incluido en el presente volumen, muestra cómo, a partir de 2000, los gobiernos asiáticos modificaron una política internacional orientada esencialmente al fortalecimiento de la Organización Mundial de Comercio (OMC), para participar en la negociación de acuerdos comerciales, sancionados por la fracción 5 del artículo XXIV del GATT. Así, la filosofía del "regionalismo abierto" propuesta por el GPE de APEC fue sustituida, en la práctica, por el regionalismo basado en el proteccionismo consensuado.

Entre 2003 y 2004, los hombres de negocios agrupados en ABAC prepararon un estudio de factibilidad sobre la Free Trade Area of Asia-Pacific (Área de Libre Comercio de Asia-Pacífico o ALCAP) y, en su reunión de 2004, en Santiago de Chile, los "líderes" por primera vez incluyeron en su declaración una mención a dicho proyecto. Hubo que esperar hasta la reunión de Lima, Perú, de 2008, para que los líderes volvieran a pronunciarse sobre el tema: 
[...] elogiamos el progreso realizado en el examen de las perspectivas y opciones de una posible Área de Libre Comercio de Asia-Pacífico (ALCAP), como un proyecto de largo plazo. Tomamos nota de los consejos de los ministros en torno a los probables beneficios económicos [del proyecto] para la región en su conjunto y a los desafíos que implica su creación. Instruimos a los ministros y funcionarios para que emprendan nuevos exámenes de las perspectivas y opciones de una posible ALCAP, incluyendo un trabajo analítico adicional sobre su probable impacto económico y discutiendo los posibles requisitos para la creación de capacidades requeridas para probables negociaciones futuras (APEC, 2008).

El año 2008 fue crucial en el desarrollo de la agenda de APEC por tres razones: la primera fue la decisión de los líderes de APEC de hacer suyo el proyecto del ALCAP, a fin de convertirlo en el medio utilizado para alcanzar la liberalización comercial y financiera pregonada en las Metas de Bogor. En efecto, ante la inminencia de 2010, los líderes, sobre todo los de los países avanzados del foro, necesitaban rendir cuentas sobre el compromiso moral contraído en 1994 y, llegado el momento, cualquier progreso realizado en dirección del ALCAP serviría para salvar la cara.

La segunda razón que justificó la importancia de 2008 fue la sustitución práctica de la liberalización comercial y financiera, unilateral y voluntaria, subyacente en el regionalismo abierto pregonado por el GPE de APEC, por el proyecto de la liberalización comercial y financiera, consensuada y en beneficio exclusivo de las economías participantes en el ALCAP. Los líderes transitaron de una filosofía liberal a una práctica regionalista basada en lo que hemos dado en calificar como proteccionismo consensuado (Ramírez Bonilla, 2019).

La tercera razón que marcó la repercusión de 2008 en la evolución de APEC fue la reorientación de la política exterior estadounidense del Medio Oriente a la región del Pacífico. Todo comenzó en febrero de ese año, con la decisión de la administración Bush de solicitar la adhesión al TPP-4. El 4 de noviembre, los estadounidenses dieron el triunfo electoral a Barack Obama y los días 19 y 20 del mismo mes George W. Bush tuvo su última participación en la reunión de líderes de APEC. Durante esta última, los representantes de Australia, Perú y Vietnam anunciaron su decisión de incorporarse al TPP-4; con ello, crearon las condiciones para que la entrante administración Obama, con la señora Hillary Clinton como secretaria de Estado, convirtiese la solicitud de adhesión al TPP-4 en la negociación de 
un nuevo acuerdo comercial que, con el tiempo, sumaría a los negociadores de 12 de las 21 economías participantes en APEC y sería utilizado como instrumento para aislar política y económicamente al gobierno chino.

\section{La relación sino-estadounidense en el marco de APEC}

En otras partes hemos insistido en que la política estadounidense contra China fue iniciada por la administración Obama y en que la administración Trump la ha llevado a la confrontación directa. En efecto, el giro hacia el Pacífico formalizado por la señora Clinton en 2011 tenía como objetivo reconstruir las alianzas con los socios asiáticos del Pacífico, con miras a aislar políticamente a China; el contenido del TPP-12 mantenía un marcado cariz antiChina y fue utilizado para buscar el aislamiento económico del gigante asiático. En APEC, la administración Obama no necesitó violentar las reglas de etiqueta del foro, en la medida en que pudo arrastrar a los gobiernos más importantes de la región del Pacífico, tras su proyecto regional.

El gobierno chino reaccionó fuera de los márgenes de APEC, para emplear el andamiaje institucional construido por los gobiernos de Asia del Pacífico e impulsar su propio proyecto de integración regional: el Regional Comprehensive Economic Partnership (RCEP). Como menciona Ramírez Bonilla en su contribución al presente volumen, fue hasta la reunión de Líderes de APEC de Beijing, en 2014, que el gobierno chino aprovechó la presidencia del foro no sólo para incluir el RCEP y el TPP-12 como vías para construir el ALCAP, sino también para proponer The Beijing Roadmap for APEC's Contribution to the Realization of the FTAAP, es decir, para poner sobre la mesa de las discusiones una estrategia china orientada a la construcción del elusivo proyecto del ALCAP.

Por primera vez, los gobiernos chino y estadounidense se erigían en campeones del libre comercio, esto es, del regionalismo basado en el proteccionismo consensuado y sancionado por el GATT, para competir por la influencia política en APEC. La irrupción de Donald Trump en la escena política estadounidense sacó de los cauces institucionales la competencia sino-estadounidense, llevándola a la confrontación directa. 
Una de las primeras medidas del señor Trump como presidente de los Estados Unidos fue el retiro del TPP-12. En los corrillos de APEC o en las representaciones diplomáticas de los gobiernos de APEC era común escuchar decir a quienes participaban en las negociaciones del TPP-12 o pensaban incorporarse a ellas que lo hacían "porque participa Estados Unidos"; así, el retiro estadounidense provocó una profunda confusión inicial entre los 11 gobiernos restantes; el gobierno japonés, como señala Alfredo Román Zavala en su contribución al presente volumen, reaccionó rápidamente para convocar nuevas rondas de negociación tendientes a suprimir los temas más controvertidos del texto impulsado por el gobierno estadounidense y el 8 de marzo de 2018, en Santiago de Chile, fue firmado el texto reformado del TPP y rebautizado como Comprehensive and Progressive Trans Pacific Partnershio Agreement (СРТРP о TPP-11); ese mismo día, en Washington, Donald Trump firmaba la primera orden para imponer tarifas sobre las importaciones estadounidenses de acero y aluminio.

Para el gobierno japonés, la recuperación del proyecto transpacífico se inscribía en una estrategia política que incluía, además de la participación en el TPP-12 y en el RCEP, la negociación de un acuerdo comercial con la Unión Europea (UE). Los observadores internacionales se apresuraron a señalar que, en el marco del TPP-11, el objetivo de Shinzo Abe era:

[...] extender el TPP para recrear, con el conjunto de los participantes, el equivalente de los 19 billones de dólares de la economía estadounidense. Corea del Sur, Indonesia, Filipinas e India son objetivos importantes. Aquí, Abe puede desempeñar un papel catalizador, revitalizando la Abenomics y haciendo que la influencia mundial de Japón vuelva a ser grande (Pesek, 2018).

Más tarde, cuando el gobierno japonés firmó el acuerdo con la UE, The Washington Post magnificó el lugar y la función de Japón en la economía internacional, mediante un artículo titulado "Japón, no Europa, es ahora el líder del libre comercio" (Lee-Makiyama, 2018). No insistiremos en el uso equívoco del término "libre comercio"; más bien, llamamos la atención sobre la ambigüedad de la posición política del gobierno nipón: por un lado, vivió un momento de gloria al ser considerado como remplazante de los Estados Unidos en la promoción de la liberalización comercial regulada mediante acuerdos comerciales 
intergubernamentales; por otro lado, esa función como promotor del proteccionismo consensuado estuvo permanentemente modulada por la relación bilateral con los Estados Unidos. Así, las concesiones hechas por el gobierno japonés a sus contrapartes del TPP-11 fueron inicialmente consideradas el alcance mínimo del acuerdo comercial bilateral Estados Unidos-Japón; sin embargo, el convenio firmado el 25 de septiembre de 2019 fue más allá de esa expectativa y las concesiones acordadas para los Estados Unidos en el sector agroalimentario, después de 15 años de estar en operación, harán de la economía japonesa la más abierta de las asiáticas; mientras eso sucede, los socios del TPP-11, del RCEP y de la Unión Europea estarán en posición de exigir el mismo trato que el concedido a los Estados Unidos. En resumen, Japón será el líder del "libre comercio" a condición de abandonar la política de apertura comercial parcial regulada por los Acuerdos de Asociación Económica promovidos, hasta ahora, por las autoridades niponas.

Finalmente, en este contexto inédito, la situación internacional de China es totalmente nueva: la confrontación directa con el gobierno estadounidense ha obligado a las autoridades chinas a entablar negociaciones para llegar a un acuerdo bilateral; al momento de escribir estas líneas, más allá de una supuesta inminencia de la culminación de las negociaciones, poco es lo que se sabe de ellas; el resultado mostrará quién ha sido capaz de imponer sus intereses sobre el contrincante. Pero la relación sino-estadounidense también es ahora modulada indirectamente por la nueva función de la economía japonesa: como indicamos, el gobierno japonés será presionado por sus socios en el TPP-11 para ampliar los beneficios del acuerdo e igualar los otorgados al gobierno estadounidense; ahora bien, como algunos socios del TPP-11 también participan en el RCEP, esas presiones se extenderán al ámbito de este acuerdo y también recaerán sobre las autoridades chinas. Las preguntas que quedan en el aire consisten en saber si la reciprocidad será la base de la respuesta del gobierno chino o si, para China, el RCEP ha nacido muerto.

Mediante su contribución, Romer Cornejo Bustamante y Francisco Haro Navejas añaden elementos que ensombrecen el panorama político internacional de China: la crisis política de Hong Kong y del proyecto "un país, dos sistemas". A eso habría que añadir las reacciones de las corrientes independentistas en Taiwán y sus repercusiones sobre el principio de "una sola China", es decir, sobre la base de la política exterior china. 
El año 2020, en consecuencia, registrará el doble fracaso de APEC: ausencia de voluntad política para contribuir a la creación de un régimen global de libre comercio (basado en la liberalización comercial y financiera, unilateral y voluntaria, pregonada por el regionalismo abierto) e incapacidad para constituir un área comercial basada en el proteccionismo consensuado (propio de los acuerdos comerciales regulados por el GATT).

En su contribución, Eugenio Anguiano concluye que, en 2020 y con el fin de eludir el fracaso, los líderes de APEC podrían afirmar haber alcanzado las Metas de Bogor, mediante una "declaración no de consenso, sino interpretativa"; para garantizar la permanencia de APEC, Anguiano sugiere que las 11 economías asociadas en el CPTPP deberían esforzarse para convertir "ese foro de cooperación voluntaria en un proceso de integración económica".

La integración económica entre miembros de APEC, no obstante, es ahora determinada en gran medida por los acuerdos bilaterales de los Estados Unidos con Corea, Canadá, México y Japón; si es correcta nuestra hipótesis sobre la influencia de las nuevas funciones de Japón en los acuerdos con los Estados Unidos, TPP-11 y RCEP, podríamos considerar un segundo escenario para la permanencia de APEC: ésta sería garantizada si y sólo si el organismo es reinventado como un foro de diálogo y de consulta en temas cooperación política (y no sólo económica) que garantice "la contención, sin aislamiento" de los Estados Unidos y de China. Para los miembros de APEC, esa función de contención de las dos potencias en pugna es tanto más necesaria cuanto la confrontación sino-estadounidense se desarrolla fuera de los marcos multilaterales y APEC se mantiene como el único foro regional donde ambos contendientes coexisten.

\section{México en el futuro de APEC o APEC en el futuro de México}

El Anuario Asia Pacífico de El Colegio de México está fundamentalmente dedicado al análisis de los procesos en curso en la región asiática del Pacífico; cuando los acontecimientos ameritan la extensión de su cobertura a otras áreas del Pacífico, el Anuario ha incluido otros estudios de caso; consideramos que el cambio de gobierno en México, en diciembre de 2018, y la política internacional de la nueva administración mexicana así como el contexto particular de APEC previo al cumplimiento de la segunda fecha de las Metas de Bogor, justifican la inclusión de un capítulo sobre México; en éste, Carlos Uscanga Prieto 
analiza la participación de México en el largo plazo y plantea dos escenarios para la participación de la administración López Obrador en el futuro inmediato de APEC.

Ese posible escenario estaría marcado por el síndrome Mexi-komori, análogo al experimentado por los hikikomori, al negarse el responsable de la rama ejecutiva del gobierno a interactuar en la sociedad internacional regida por reglas estrictas de comportamiento; el resultado sería la retrotracción de la política exterior a espacios internacionales mínimos, como consecuencia de la negación del titular del Ejecutivo a participar en las instancias multilaterales.

El escenario deseable estaría basado en una proactividad internacional del titular del Ejecutivo que permitiría apuntalar una estrategia doméstica de desarrollo con mecanismos internacionales de cooperación y de integración económica.

Uscanga subraya la nueva coyuntura abierta por el United States-Canada-Mexico Agreement (USCMA), para considerar las desventajas del escenario posible y las ventajas del escenario deseable; en ese sentido, consideramos que APEC, ya sea como una futura iniciativa de integración o como un renovado proyecto de cooperación intergubernamental, permitiría ir más allá de la relación con los Estados Unidos, para sacar las mayores ventajas del USCMA, a partir de la redefinición de los vínculos económicos de México con Canadá, Corea y Japón, en primera instancia, y, en segunda, con el resto de las economías de APEC; por supuesto, el factor condicionante sería la realización del escenario deseable planteado por Uscanga Prieto.

\section{ASIA DEL PACÍFICO EN EL FINAL DE LA SEGUNDA DÉCADA DEL SIGLO XXI}

En el pasado reciente era común escuchar afirmaciones sobre el siglo XXI como el siglo del Pacífico. Hoy, los éxitos económicos asiáticos parecen haber alcanzado sus límites y las perspectivas de crecimiento son poco halagüeñas en la gran mayoría de los casos; con ello, la morosidad económica internacional resultante de la crisis financiera de 2008-2010 se acentúa y es reforzada por una multiplicidad de factores políticos; al finalizar la segunda década del siglo XXI, el rasgo novedoso es la frágil estabilidad económica y política en la región del Pacífico, derivada de la disputa comercial sino-estadounidense. Las repercusiones 
negativas de ésta en Asia del este, a su vez, son reforzadas por las ondas de choque de las relaciones intercoreanas, por el conflicto político nipo-coreano derivado de las nuevas exigencias coreanas de compensaciones para trabajadores forzados durante la guerra del Pacífico y por las repercusiones internacionales de la crisis política de Hong Kong. En Asia del sureste, la expansión de la presencia de China en el Mar del Sur de China sigue siendo el principal factor perturbador de la estabilidad subregional.

\section{La disputa comercial sino-estadounidense}

Esta disputa es el principal factor que ha puesto fin al statu quo prevaleciente en la región del Pacífico desde el final de la Guerra Fría. Un orden regional que permitió el ascenso de Japón como la tercera economía mundial, primero, y, luego, de China como la segunda economía más grande del mundo. Como señalan Juan Felipe López Aymes y Jorge Raúl Suárez Campero en su contribución, para Corea la disputa comercial sino-estadounidense es crucial: se trata de sus dos socios comerciales más importantes, y las grandes empresas coreanas dependen de las exportaciones de capitales, bienes y servicios hacia ambas economías; en consecuencia, las autoridades y las empresas coreanas deberán ahora adoptar prácticas de localización territorial flexibles, para sortear una muy posible prolongación de la confrontación entre los dos gigantes.

Para Taiwán, nos dice Itzel Martínez Ruiz, la confrontación comercial sinoestadounidense fue doblemente positiva pues "creó áreas de oportunidad económica y política [...] En algunos sectores industriales, Taipéi se benefició de las sanciones económicas impuestas por los Estados Unidos a las importaciones chinas y, en la esfera política, el gobierno taiwanés aprovechó la coyuntura para fortalecer y estrechar su relación con los Estados Unidos”. El reto para el gobierno taiwanés consiste en reducir la dependencia de las empresas taiwanesas respecto al mercado chino; queda por ver hasta dónde dispone de medios para limitar esa dependencia estructural que, ante el acoso de los Estados Unidos sobre China, podría convertirse en el talón de Aquiles del régimen taiwanés.

Juan Carlos Calleros Alarcón pone de realce la posición central de Singapur en múltiples macroacuerdos comerciales: ASEAN-FTA, TPP-4, CPTPP, RCEP; esa centralidad podría ser considerada una ventaja ante las repercusiones del conflicto comercial sino- 
estadounidense; sin embargo, no debemos olvidar que Singapur es una fuente destacada de inversiones directas para la economía china y que las empresas singapurenses localizadas en China podrían verse obligadas a refugiarse en otros países ante el mantenimiento o el incremento de las barreras para el acceso de sus bienes o servicios al mercado estadounidense.

En el caso de Malasia, en referencia a la participación en los grandes acuerdos comerciales regionales, Dulce María Moncada García señala la situación análoga a la de Singapur; sin embargo, también señala los movimientos pendulares del Mohamad Mahathir en relación con la Road \& Belt Initiative (R\&BI) del gobierno chino, para acabar siendo apabullado por el peso de China y de las grandes empresas chinas en el comercio exterior malasio. En ese sentido, es posible encontrar una diferencia cualitativa entre la relación sinosingapurense y la relación sino-malasia: mientras en la primera pesan grandemente empresas singapurenses, en la segunda lo hacen empresas chinas; la consecuencia necesaria es la mayor dependencia de Malasia de la economía china.

Un segundo aspecto señalado por Moncada García es que el gobierno de Malasia ejercerá la presidencia pro tempore de APEC durante 2020. Después de la incapacidad de los líderes del foro para emitir una declaración conjunta en 2018 y de la suspensión de la reunión de líderes en 2019, tendrá la responsabilidad de maquillar el fracaso en la realización de las Metas de Bogor como un éxito; el mundo estará atento para evaluar el desempeño del gran polemista Mohamad Mahathir en ese terreno; en esta ocasión hará falta algo más que retórica para superar el escollo y garantizar la permanencia del foro.

Para el gobierno de Tailandia, señala Pablo H. Ramírez D., existe una actitud bivalente en relación con el conflicto sino-estadounidense; esto es la resultante de una alianza estratégica con los Estados Unidos como garantes de la neutralidad tailandesa en los grandes temas internacionales y regionales, y de una relación económica creciente con China sostenida por la presencia de grandes empresas chinas en la economía tailandesa y por la participación financiera china en grandes proyectos de infraestructura en los países del sureste de Asia continental. Para Ramírez D., la alianza thai-estadounidense necesitaría ser renovada, aprovechando los espacios económicos, políticos y militares que ofrecen las iniciativas recientes de los gobiernos de ambos países; esto es tanto más urgente debido a que 
el gobierno chino ha sabido aprovechar las coyunturas propicias para ganar la confianza del régimen militar tailandés y de sus bases sociales.

Indonesia es un segundo caso en que la neutralidad ante la confrontación comercial sino-estadounidense es manifiesta; en gran medida, el texto de Fernando Octavio Hernández Sánchez deja entrever el trasfondo histórico de esa neutralidad: el respaldo chino al régimen de Sukarno parece pesar tanto en la memoria histórica de las clases dominantes indonesias como en la actitud política del presidente Joko Widodo; de allí que, señala Hernández Sánchez, el gobierno indonesio haya tardado en incorporarse a la R\&BI, sin dejar la iniciativa libre al gobierno chino para consolidar su presencia militar en el Mar del Sur de China, donde Indonesia también mantiene reivindicaciones sobre una parte del espacio marítimo. El gobierno indonesio ha sido de los pocos que han expresado formalmente su oposición a que "APEC se convierta en un foro empleado por los Estados Unidos y China para proyectar su rivalidad económica" y su invitación a los demás gobiernos del foro "para mantener una postura neutral ante tal contienda”. En opinión de Hernández Sánchez, en relación con 2020 el gobierno indonesio es escéptico en cuanto a la realización de las Metas de Bogor; pese a ello y dado el peso económico y político de Indonesia en ASEAN, el gobierno podrá influir en la renovación del foro a partir de la reunión de 2020, a realizarse en Malasia.

\section{Las disputas intergubernamentales en Asia del este}

La creciente influencia regional de China suele dejar en la sombra los acontecimientos que se producen en las subregiones del Pacífico asiático. Tal es el caso del este asiático, donde se encuentran enclavadas, además de la china, las economías japonesa, coreana y taiwanesa, así como las Regiones Administrativas Especiales de Hong Kong y de Macao. En esta área, la conjunción de factores globales, regionales y locales ha renovado los diferendos históricos intergubernamentales. Durante 2019, tres crisis internacionales han influido sobre el statu quo regional: la carrera nuclear en Corea del Norte y las relaciones intercoreanas, la escalada del diferendo nipo-coreano y la crisis política de Hong Kong. 


\section{La carrera nuclear en Corea del Norte y las relaciones intercoreanas}

En su momento, las reuniones Donald Trump-Kim Jung-un parecieron favorables para desactivar uno de los focos críticos de Asia del este. El dirigente norcoreano se comprometió a dar por terminado el programa nuclear, así como a desmantelar las instalaciones nucleares de Yongbyong, mientras su contraparte estadounidense prometió poner fin a las sanciones contra el régimen comunista norcoreano. López Aymes y Suárez Campero ponen de realce el incumplimiento de los compromisos contraídos: ni el gobierno de los Estados Unidos levantó las sanciones ni el gobierno norcoreano puso término al programa nuclear; la consecuencia ha sido la disminución progresiva de los contactos bilaterales hasta su suspensión de facto.

Si bien es cierto que el régimen norcoreano ya no ha realizado pruebas nucleares, también lo es que ha reanudado su programa balístico y, entre el 4 de mayo y el 28 de noviembre de 2019, en diez ocasiones realizó lanzamientos de diferentes clases de misiles, entre los cuales había uno de mediano alcance y otro lanzado desde un submarino. La alarma fue activada por los vecinos en cada ocasión, sin que haya habido alguna reacción efectiva contra el gobierno de Kim Jung-un; con ello quedó manifiesta la inefectividad de la política sobre la bilateralización de las relaciones internacionales puesta en práctica por la administración Trump.

Más allá de los compromisos no cumplidos ni por la administración Trump ni por el gobierno de Kim Jung-un, las reuniones bilaterales le permitieron a este último obtener el reconocimiento como interlocutor legítimo para reinsertarse en el sistema internacional. Con ello parecería que las relaciones intercoreanas evolucionan ahora en una senda diferente: con un gobierno del norte más interesado en la consolidación de su independencia y su suficiencia, y con un gobierno del sur todavía interesado en la unificación de la península, como si el contexto fuese el mismo de hace dos años. En consecuencia, es de esperar que, cuando menos en el corto y mediano plazos, la península coreana siga siendo un foco de tensión. 


\section{Corea-Japón}

Un segundo tema internacional ha impactado a Corea: la escalada del diferendo nipo-coreano desde la exigencia de compensaciones monetarias para ciudadanos coreanos a quienes los tribunales coreanos juzgaron de haber sido sometidos a trabajos forzados durante la guerra del Pacífico, hasta el embargo comercial nipón de insumos requeridos por las empresas coreanas para la producción de semiconductores. López Aymes y Suárez Campero señalan que, a partir de mayo de 2019 y con el objetivo de resolver la crisis, los contactos bilaterales entre funcionarios de alto nivel se han multiplicado, incluyendo reuniones entre el presidente Moon Jae-in y el primer ministro Abe Shinzo.

Este conflicto muestra la delgada y frágil barrera que separa las diferentes áreas de acción intergubernamental; la escalada, por el momento, ha sido detenida. Pero para el gobierno japonés el tema es potencialmente delicado; pues, señalan los autores del ensayo sobre Corea, casos como el de los coreanos existen en países tanto del este como del sureste asiático; en ese sentido, la decisión de los tribunales coreanos sería un antecedente jurídico para dar cauce a otras demandas análogas.

Cierto es que, sin importar el tiempo necesario para revolver el conflicto bilateral, tres aspectos deben ser resaltados: en primer término, la rápida transición de lo político a lo económico muestra la disposición de los gobiernos a echar mano de los factores que más puedan lastimar los intereses de la contraparte para obligarla a volver a la posición inicial. En este contexto, la autolimitación deviene un elemento esencial para evitar una escalada incontrolada de los conflictos. Pero la pregunta en el aire consiste en saber si la autolimitación funcionará en cualquier situación.

El segundo aspecto relevante es el impacto de las restricciones impuestas por las autoridades niponas a las importaciones provenientes de Japón de las empresas coreanas de los sectores industriales clave. El efecto sobre el desempeño exportador de la últimas es medible de inmediato; sin embargo, quedaría por ver si, en las redes productivas internacionales, se ha producido una sustitución de las empresas coreanas por empresas de otras nacionalidades. 
El tercer aspecto es el círculo vicioso existente, en Japón y en Corea, entre las percepciones sociales sobre los otros y el uso de los conflictos bilaterales para reforzar esas percepciones. López Aymes y Suárez Campero resaltan “el manejo político y discursivo" de la crisis por parte del gobierno coreano, para legitimarse popularmente, sin parar mientes en que dicho manejo alimenta y refuerza las percepciones negativas de los otros. Esto trae a la mesa de discusiones el tema del nacionalismo en la era de la interdependencia global.

\section{El impacto de la crisis política de Hong Kong}

En el contexto global marcado por la confrontación sino-estadounidense se produjo la profunda crisis política que ha marcado la relación entre el gobierno chino y la población de Hong Kong. Todo comenzó en febrero de 2019 con la presentación de la ley para extraditar criminales a China; la población la entendió como un medio para enviar opositores hongkoneses al gobierno chino a las cárceles del continente; fuerte del respaldo de la autoridad central de Beijing, la responsable de la autoridad ejecutiva hongkonesa mostró insensibilidad ante las primeras protestas y éstas se ampliaron progresivamente, manteniéndose hasta el momento de escribir estas líneas y a pesar del retiro del proyecto de ley, el 23 de octubre de 2019.

El impacto político de las protestas ha sido múltiple. En el plano doméstico, en primer término, Carrie Lam quedó políticamente desacreditada y la población ha exigido reiteradamente su renuncia. En segundo lugar, como señalan Cornejo y Haro, el movimiento de protesta pasó de exigir el retiro de la ley de extradición a demandar el cumplimiento de un pliego petitorio de cinco puntos, mostrando el grado de politización de la protesta popular. En tercera instancia, la elección de los consejos de distrito del 24 de noviembre confirmó el grado de politización y el distanciamiento de la población respecto a las autoridades hongkonesas y los candidatos considerados proclives a Beijing.

En el ámbito internacional, los efectos políticos repercutieron en la relación entre el gobierno central de Beijing y grandes sectores de la población hongkonesa que reivindican el respeto de su identidad y que no están dispuestos a aceptar las imposiciones políticas del gobierno central. En términos más amplios, como se ha indicado anteriormente, la crisis de Hong Kong ha puesto en tela de juicio el proyecto de Beijing, basado en el principio de "Un 
país, dos sistemas". La población hongkonesa y los medios internacionales han interpretado que lo que está en juego en la disputa es la voluntad china de homogeneizar políticamente el continente y sus Regiones Administrativas Especiales, para borrar las diferencias económicas, políticas y sociales entre el sistema imperante en Hong Kong y el prevaleciente en el continente.

La onda de choque de la protesta popular en Hong Kong también ha afectado la política de "una sola China", pues, como señala Itzel Martínez Ruiz, el curso de la campaña electoral para la elección presidencial de 2020 en Taiwán fue modificado en detrimento de Han Kuo-yu, apoyado por el Kuomintang (KMT), proclive a Beijing, y en beneficio de la actual presidenta Tsai Ing-wen, sostenida por el Partido Demócrata Progresivo. Aun cuando esta última no es abiertamente proindependencia, el fortalecimiento de su campaña se debe al apoyo recibido de sectores sociales independentistas o políticamente distantes de Beijing.

La presidenta Tsai ha llamado la atención sobre el riesgo de la intervención china en el próximo proceso electoral taiwanés, para beneficiar a la facción política que le es favorable y, señala Martínez Ríos, recién propuso una "ley antiinfiltración que prohíbe a cualquier actor externo (haciendo referencia a China) hacer donaciones a los partidos políticos taiwaneses".

Fuera del área de la Gran China, figuras como el primer ministro malasio, Mohamad Mahathir, consideraban necesaria la renuncia de la señora Carrie Lam como salida al dilema entre "obedecer a sus amos y al mismo tiempo [...] responder a su propia conciencia" (Reuters, 2019). Por supuesto, desde Washington y Londres los actores políticos y los medios arremetieron contra Beijing y apoyaron el movimiento de protesta.

\section{Los procesos en el Mar del Sur de China}

Otro tema ligado al ascenso regional de China es su presencia en el Mar del Sur de China. En el sureste de Asia, el tema concierne directamente a los gobiernos de Brunéi, Filipinas, Vietnam, Malasia e Indonesia, y ha provocado una carrera armamentista para equilibrar la presencia militar china en el área. En días pasados, el gobierno de Indonesia anunció la compra de pertrechos militares aéreos y marítimos para reforzar su capacidad de respuesta ante la creciente presencia de China. 
Por si eso no bastara, durante la campaña electoral que llevó a la derrota del Barisan Nasional (Frente Nacional) en Malasia, el frente opositor prometió a los partidos políticos de Sabah y Sarawak revisar el estatus político de ambos estados dentro de la Federación de Malasia. Una vez en el poder, el Pakatan Harapan (Alianza de la Esperanza) se olvidó de la promesa, despertando veleidades independentistas en ambos territorios. La sacudida de la Federación de Malasia provocará, por necesidad histórica, reacciones en Brunéi, Filipinas e Indonesia, añadiendo un factor adicional de inestabilidad en la región.

En resumen, la disputa comercial sino-estadounidense es determinada y a la vez determina un contexto marcado por conflictos internacionales que fragilizan la estabilidad política y económica de la región del Pacífico. El siglo XXI será del Pacífico, pero la tercera década estará marcada por la multiplicación de esos conflictos; la transición de la pax americana a la pax sinica no es del todo clara y, más bien, la región se adentra en una fase de inestabilidades crecientes. Hoy, más que nunca, un foro como APEC puede contribuir a desactivar algunos de esos conflictos, si y sólo si es capaz de reinventarse como un foro de diálogo y consulta, para la cooperación política intergubernamental.

Para terminar, hay que recordar a los lectores que los trabajos temáticos y monográficos incluidos en el presente volumen son ricos en información sobre los procesos en curso en cada uno de esos diez países del Pacífico asiático y a ellos los remitimos para conocer las especificidades de las coyunturas nacionales durante 2019.

\section{REFERENCIAS}

APEC (1993). A Vision for APEC: Towards an Asia Pacific Community, 1993. Disponible en https://www.apec.org/Publications/1993/12/A-Vision-for-APEC-Towards-an-AsiaPacific-Economic-Community-1993

APEC (2008). 2008 Leaders' Declaration. Disponible en https://www.apec.org/MeetingPapers/Leaders-Declarations/2008/2008_aelm

Expansión (2019). "India aprueba una ley de ciudadanía que excluye a los musulmanes". Disponible en https:/expansion.mx/mundo/2019/12/11/india-aprueba-una-ley-deciudadania-que-excluye-a-los-mulsulmanes 
Lee-Makiyama, Hosuk (2018). "Japan, not Europe, is now the leader of free trade". Disponible en https:/www.washingtonpost.com/news/theworldpost/wp/2018/08/10/ japan-free-trade/

Pelosi, Nanci (2019). “T-MEC es infinitamente mejor que TLCAN: Nanci Pelosi”. Disponible en https://www.eluniversal.com.mx/mundo/t-mec-es-infinitamente-mejor-que-el$\underline{\text { tlcan-nancy-pelosi }}$

Pesek, William (2018). "How Abe can make TPP great again. Japan can expand the club, save free trade and promote growth". Disponible en https://asia.nikkei.com/Opinion/HowAbe-can-make-TPP-great-again

Ramírez Bonilla, Juan J. (2019). "La administración Trump y la transición del proteccionismo consensuado al proteccionismo coercitivo”. En León Manriquez, José L. (coord.). Asia-Pacífico: poder y prosperidad en la era de la desglobalización. Universidad Autónoma Metropolitana-Xochimilco (en prensa).

Reuters (2019). "Malaysia's Mahathir says Hong Kong leader should step down: report”. Disponible en https://www.reuters.com/article/us-hongkong-protests-malaysia/ malaysias-mahathir-says-hong-kong-leader-should-step-down-report-idUSKBN1W J0NK

Sen, Amiti (2019). "India refuses to sign up for RCEP; says its core concerns remain unresolved". Disponible en https://www.thehindubusinessline.com/economy/indiasays-no-to-rcep-as-its-concerns-remain-unaddressed/article29880428.ece\#

Trump, Donald (2017). Remarks by President Trump at APEC CEO Summit, Da Nang, Vietnam. Disponible en https://www.whitehouse.gov/briefings-statements/remarkspresident-trump-apec-ceo-summit-da-nang-vietnam/ 